\title{
Will Nzoia Basin in Kenya See Water Deficiency in Coming Decades as a Result of Climate Change
}

\author{
Pradeep Adhikari ${ }^{1,2,3}$ and Yang Hong ${ }^{2,3^{*}}$ \\ ${ }^{1}$ Department of Geography and Environmental Sustainability, University of Oklahoma, \\ Norman, Oklahoma. \\ ${ }^{2}$ School of Civil Engineering and Environmental Science, University of Oklahoma, Norman, \\ Oklahoma. \\ ${ }^{3}$ Atmospheric Radar Research Center, University of Oklahoma, Norman, Oklahoma.
}

Authors' contributions

This work was carried out in collaboration between authors $P A$ and $Y H$. Author PA designed the study along with author $Y H$, conducted data analysis and modeling, and prepared the manuscript. Author YH oversaw the whole process as the research advisor. There were series of interactions between the authors to prepare and revise the manuscript.

Research Article

Received $5^{\text {th }}$ May 2012 Accepted $16^{\text {th }}$ October 2012 Published $10^{\text {th }}$ April 2013

\section{ABSTRACT}

This study investigates the potential change in the hydrologic cycle in Nzoia basin, one ofthe semi-arid basins of east Africa. An ensemble of 16 Global Climate Models data under different emissions scenarios are used in this study. The basin is expected to receive an increase in precipitation in all scenarios; from $5 \%$ to $15 \%$ by theend of this century compared to the base period 1990-1999. However, a 2 to $5^{\circ} \mathrm{C}$ increase in temperature is expected to create an overall drier climate with reduced runoffs. The decadal averaged seasonal trends show that all major hydrological components except the runoff are expected to increase. An increase in temperature, together with more precipitation, could significantly increase actual evapotranspiration, ultimately may result a decrease in runoff by $14 \%$ and $18 \%$ in the 2020 s and 2090 s respectively compared to the base period. The elasticity analysis showed that the change in runoff is more sensitive to a change in temperature than precipitation for the 2060s and 2090s; and suggested that temperature will continue to be the dominating factor in future climate. In general, Nzoia will very likely experience a drier climate, further exacerbating the

*Corresponding author: Email: yanghong@ou.edu; 
biomass production and food security.

Keywords: Climate change; hydrology; arid climate; climate elasticity; food security; drought.

\section{INTRODUCTION}

One of the major concerns of climate change is its impact on water resources. The Intergovernmental Panel on Climate Change's (IPCC's) Fourth Assessment Report cites an overall negative impact of climate change on water resources [1]. Furthermore, an increased stress on water resources from population growth and land-use change is also expected to worsen the impact. By the 2020s about half a billion people could see increased water resources stress as a result of climate change [1,2]. The severity and extents of such impacts are expected to vary around the world. The annual average river runoff and water availability is expected to increase at high latitudes and in some wet tropical areas while it is expected to decrease over some dry regions at mid-latitudes and in the dry tropics for the middle of the 21st century [3]. Climate change is also expected to exacerbate vulnerability of communities from extreme events like floods and droughts. Areas in which runoff is projected to decline are likely to face a reduction in the value of the services, like irrigation and water supply, provided by water resources. The losses of services and associated risks will have direct and indirect effects on economic development and human wellbeing. It is predicted that by 2050, extreme weather could reduce global Gross Domestic Product (GDP) by $1 \%$ and unabated, climate change could cost the world at least $5 \%$ in GDP each year [4].

Climate induced changes in both the seasonal runoff and inter-annual runoff variability can be just as important for water availability as changes in the long-term average annual runoff. A warmer climate is expected to intensify the hydrologic cycle, altering precipitation and the timing of run-off. Air parcels of higher temperatures allow more evaporation to take place; hence the increased evaporation of soil moisture leads to an increase in water vapor content $[1,5]$. With more moisture in the atmosphere, rainfall and snowfall events tend to be more intense, increasing the potential for flooding. In contrast, drought occurs due to prolonged lack of precipitation causing soils dry. Any further solar radiation dehydrates the soil. Consequently, efforts to investigate the hydrological cycle and water availability in a changing climate hold great importance to understand the impacts of climate change. The impacts of climate variability manifested in prolonged droughts, floods, unseasonal rains and extreme climatic events create enormous challenges to the countries around the world and especially the developing countries with limited resources [6,7]. Africa is particularly vulnerable to the effects of climate change, including reduced agricultural production, worsening food security, the increased incidence of both flooding and drought, spreading disease and an increased risk of conflict over scarce land and water resources[4,8].Climate has had a significant and negative effect on economic growth in Sub-Sahara Africa [9]. In Kenya alone the drought of 1999-2001 cost the Kenya economy some 2.5 billion dollars [10]. Much of the Sub-Sahara Africa including Kenya has a history of droughts. The drought may deteriorate further as climate change models also indicate the likely increase in drought severity during the 21st century [11] and likely increasing the food insecurity. The food security aspect is more vulnerable in the changing climate as dependence on rain-fed agriculture is prevalent inAfrica. According to the Food and Agriculture Organization of the United Nations as of 2009 only about $5 \%$ of the cultivated lands in Africa are irrigated. The disparity in the irrigation provision is also much wider in different parts of Africa. The northern part has about $23 \%$ cultivated lands irrigated while this number is only $3 \%$ in Sub-Saharan 
Africa [12]. Overdependence on rain-fed agriculture make these regions more vulnerable to climate change which is further exacerbated by socio-economic factors like poverty and weak capacity to recover from natural hazards. In Nzoia, agricultural areas in 2000 have decreased by about $17 \%$ compared to 1986 , mainly due to changing weather patterns [13]. The situation is likely to continue over the coming decades as the runoff is expected to decrease along with the land degradation [14].

Over the past two decades research on climate change and its impacts on water resources have been one of the overarching themes of climate impact studies. Such impacts are either poorly understood or interpreted far too qualitatively in terms of what one can expect from the changing climate to their environment and livelihood. Such studies in marginalized developing regions of the world are greatly needed but unfortunately limited [15, 16]. Discussions on the impacts of climate change in those regions are therefore centered on a very general assumption of cause (low or high precipitation, decrease or increase in temperature etc.) and effect (drier or wetter climate, drought or flooding etc.) of scenario and extrapolation of conditions in the coming decades. Still, the majority of the people in these regions rely more on climate-sensitive natural resources, such as rain-fed agriculture, pastoralism, forestry and wetlands. Furthermore, they have a poor capacity to withstand and recover from storms, floods, droughts, and disease outbreaks naturally or as a result of climate change. This is the motivation for current research. This study intends to fill an existing knowledge gap on the impact of climate change through a case study of the Nzoia basin of Kenya, a vulnerable agricultural region in East Africa. The objectives of this study are to: determine the projected precipitation and temperature change in the basin under three different emissions scenarios: A2, A1B and B1 [17] over the base period of 1990-1999, ascertain anticipated changes over the basins in terms of evapotranspiration and runoff for 2020-2029, 2060-2069 and 2090-2099 compared to the base period of 1990-1999 and assess the changes of water availability in the rain-fed agricultural region.

\section{MATERIALS AND METHODS}

\subsection{Study Area}

The Nzoia basin is located at latitudes $34^{\circ}-36^{\circ} \mathrm{E}$ and longitudes $0^{\circ} 03^{\prime}-1^{\circ} 15^{\prime} \mathrm{N}$ in Western Kenya and covers an area of about $12,900 \mathrm{~km}^{2}$. The basin elevation in the area ranges from 1,100 to $4,000 \mathrm{~m}$ (Fig. 1). The basin, with a semi-arid climate, is one of the major contributing sub-basins of Lake Victoria in the East African highlands. Mean annual rainfall varies from 850 to $1,900 \mathrm{~mm}$. The region experiences four seasons due to the inter-tropical convergence zone (ITCZ), however, the local relief and influences of Lake Victoria modify the regular weather patterns. The Nzoia River drains into the Lake Victoria and ultimately to Nile river basin. The Nzoia River is a major source of water for more than three million people in western Kenya. The river also supports agriculture and commercial sectors in the region. This region is an important cereal and sugarcane-farming region of Kenya, producing at least $30 \%$ of the national output of both maize and sugar [18]. The Nzoia River basin ecosystem supports not only western Kenya but also the broader Lake Victoria region. 


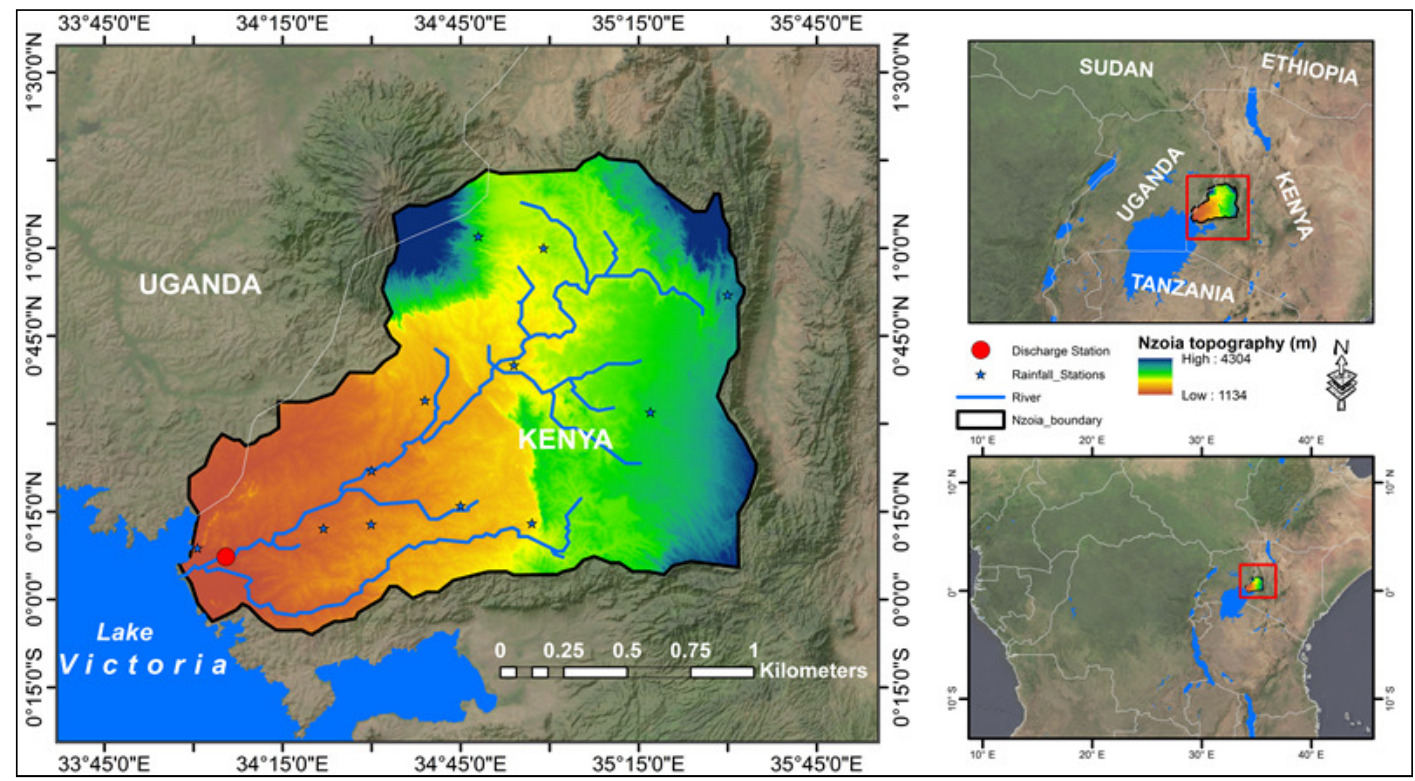

Fig.1. The location of the Nzoia river Basin in Kenya along with the discharge and rain gauge stations are shown (Left panel). The location of Kenya and the study basin with respect to the African Continent (Right panel)

Kenya's climatic conditions vary across the regions. A humid tropical climate prevails along the coast of the Indian Ocean and surrounding areas of Lake Victoria while the inlands are arid. The mean temperature varies with elevation. The variation of precipitation is dramatic mainly due to its geographical location. Kenya experiences a bimodal seasonal pattern in precipitation as it lies across the equator: the long rainy season starts around March and runs through to June, with the peak centered on March to May; the shorter rainy occurs from September to November (or December) due to the shift of the Inter-Tropical Convergence Zone. Rainfall is correlated to topography; for example the highest elevation regions receive up to $2,300 \mathrm{~mm}$ of rainfall per year while the lower plateau receives only about $320 \mathrm{~mm}$ a year. Over two-thirds of the country receives less than $500 \mathrm{~mm}$ of rainfall. The annual rainfall generally follows a strong seasonal pattern, with variations being strongest in the dry lowlands of the north and east, but weakest in the humid highlands of the Central and Rift Valley areas. The intensity and spread of the rainfall in each region determines the effectiveness of the rainfall. The average annual temperature ranges from about $10^{\circ} \mathrm{C}$ to about $30^{\circ} \mathrm{C}$. Mean temperatures in Kenya are closely related to ground elevation. Annual temperature variations are generally small (less than $5^{\circ} \mathrm{C}$ ) throughout the country. In the study area of Nzoia basin temperature varies between 18 to $21^{\circ} \mathrm{C}$.

\subsection{Data}

The main source of climate data for the study includes precipitation ( $\mathrm{mm} / \mathrm{month}$ ) and temperature $\left({ }^{\circ} \mathrm{C}\right)$ data from the 16 Global Climate Models at $0.5^{\circ} \times 0.5^{\circ}$ resolutions, which were made available through the World Climate Research Program's (WCRP) Coupled Model Intercomparison Project 3 (CMIP3)[19]. The data covers the period from 1950 to 2099. The data are available for the A2, A1B and B1 Special Report Emissions Scenario (SRES). There are some recent studies utilizing this product in the United States 
$[20,21]$.Each scenario represents a different prediction of the effects of greenhouse emissions depending on factors such as population growth, economic development and technological change. A2 is the most aggressive, A1B is the balanced and B1 is the most conservative emission scenario [17]. The basin average temperature and precipitation data over the study basin are extracted for A2, A1B and B1 SRES.

The in-situ data for this study included daily precipitation measurements (1985-2006) from the 12 rain gauge stations located within the basin. Also obtained were the daily discharge data (in $\mathrm{m}^{3} / \mathrm{sec}$ ) at the basin outlet for the same time period. These daily datasets were accumulated to a monthly scale. For the purpose of this research, the data at the individual stations were averaged over the basin. The monthly temperature in-situ data is available from only one station within the Nzoia basin from the World Meteorological Organization (WMO). The precipitation data from 1985-2006 does not show any pronounced bimodal rainy seasons in Nzoia but a marked rainy season is observable from March to June, which peaks on April and May. A subdued rain peaks on August, October and November (Fig. 2a). The observation data for 1985-2006 shows the typical tropical climatic pattern in the basin (Fig. 2b). The basin average runoff coefficient, which gives the ratio between runoff and rainfall calculated on the basis of 1985-2006 data, is about 0.4, which shows basin's dryness. The runoff coefficient represents a complex interaction of rainfall with the ground cover and slope, soil moisture and soil types among others while generating the runoff.

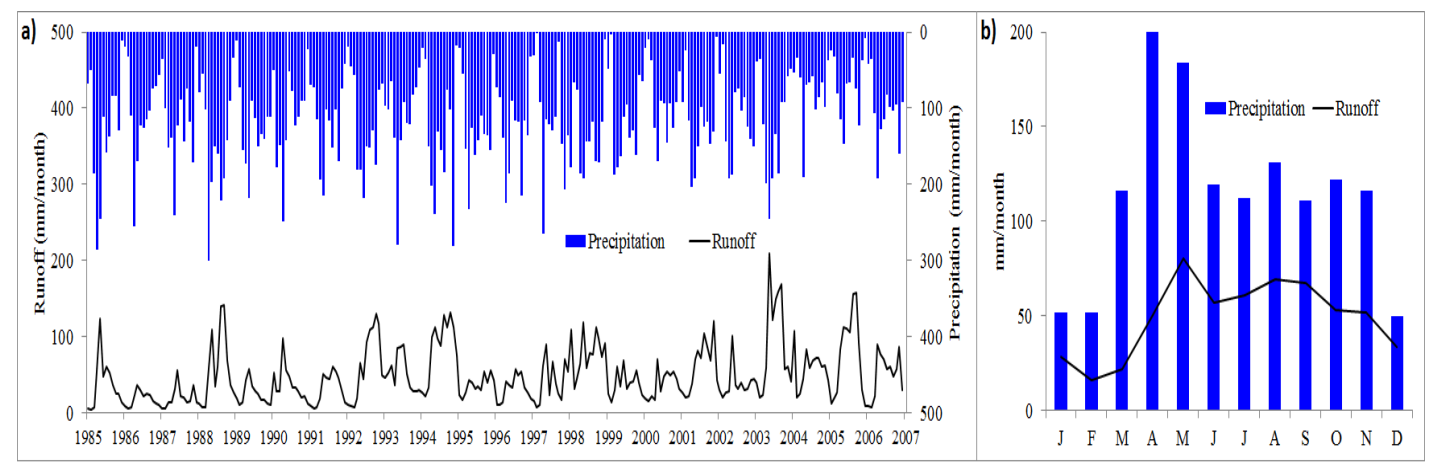

Fig.2. a) Monthly precipitation ( $\mathrm{mm} /$ month) and runoff ( $\mathrm{mm} / \mathrm{month})$ over the Nzoia basin and b) Variability in average monthly precipitation and runoff

\subsection{Methodology}

\subsubsection{Data validation}

This study utilized the bias-corrected and spatially downscaled climate projections: monthly temperature and precipitation are derived from CMIP3 data $[19,22,23]$ First, the CMIP3 data were extracted for the Nzoia basin and further validated with the ground data. For the A2, A1B and B1 scenarios, the basin average monthly precipitation $(\mathrm{mm} / \mathrm{month})$ and monthly temperature $\left({ }^{\circ} \mathrm{C}\right)$ were first validated with the in-situ data. The validation period of 1985-2006 was selected based on time periods for which in-situ data are available. It was found that the CMIP3 had underestimated the temperature (Fig. 3) and precipitation (Fig. 4) by about 3\% and $7 \%$ respectively. 

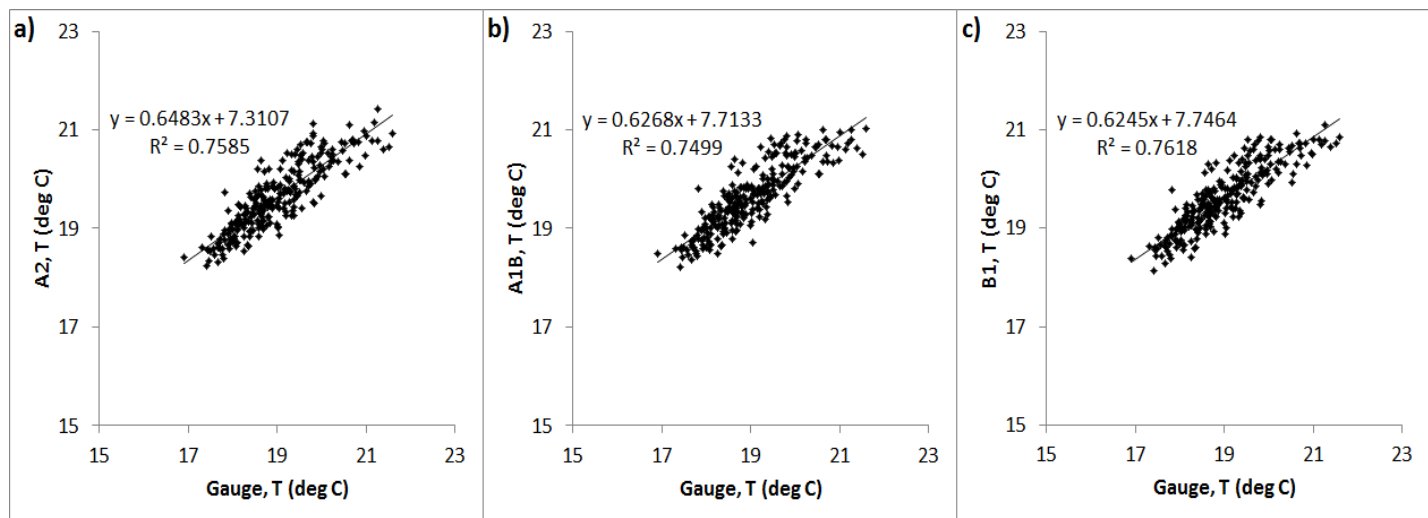

Fig. 3. CMIP3 vs. gauge temperature for 1985-2006 a) A2, b) A1B and c) B1
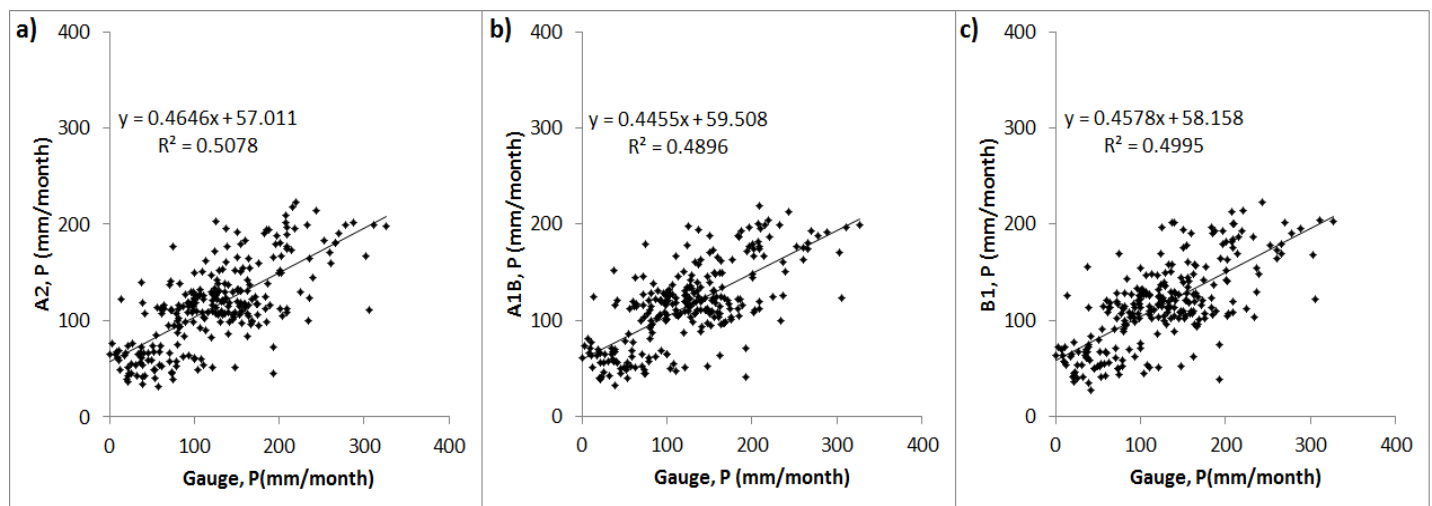

Fig. 4. CMIP3 vs. gauge precipitation for 1985-2006, a) A2, b) A1B, and c) B1

As the CMIP3 data is downscaled using gridded $\left(2^{0} \times 2^{0}\right)$ observed data for 1950-1999 [22] another round of bias correction is applied using the observed data of 1985-2006, which further improved the downscaled climate projections over the basin (Table 1 and 2).

Table 1. Bias correction of predicted temperature improved validation indices

\begin{tabular}{lllll}
\hline Scenario & Condition & $\begin{array}{l}\text { Correlation } \\
\text { Coefficient } \\
\text { (CC) }\end{array}$ & $\begin{array}{l}\text { Bias } \\
(\%)\end{array}$ & $\begin{array}{l}\text { Root Mean } \\
\text { Square Error } \\
\text { (RMSE) }\end{array}$ \\
\hline A2 & Before bias correction & 0.87 & -3.31 & 0.78 \\
& After bias correction & 0.87 & -0.04 & 0.49 \\
A1B & Before bias correction & 0.87 & -3.28 & 0.78 \\
& After bias correction & 0.87 & -0.01 & 0.50 \\
B1 & Before bias correction & 0.87 & -3.22 & 0.77 \\
& After bias correction & 0.87 & -0.04 & 0.49 \\
\hline
\end{tabular}


Table 2. Bias correction of predicted precipitation improved validation indices

\begin{tabular}{|c|c|c|c|c|}
\hline Scenario & Condition & $\begin{array}{l}\text { Correlation } \\
\text { Coefficient } \\
\text { (CC) }\end{array}$ & $\begin{array}{l}\text { Bias } \\
(\%)\end{array}$ & $\begin{array}{l}\text { Root Mean } \\
\text { Square Error } \\
\text { (RMSE) }\end{array}$ \\
\hline \multirow[t]{2}{*}{ A2 } & Before bias correction & 0.71 & -7.42 & 47.82 \\
\hline & After bias correction & 0.71 & 0.50 & 43.08 \\
\hline \multirow[t]{2}{*}{ A1B } & Before bias correction & 0.70 & -7.31 & 48.64 \\
\hline & After bias correction & 0.70 & 0.61 & 43.87 \\
\hline \multirow[t]{2}{*}{ B1 } & Before bias correction & 0.71 & -7.17 & 48.14 \\
\hline & After bias correction & 0.71 & 0.76 & 43.45 \\
\hline
\end{tabular}

\subsubsection{Bench marking basin hydrology}

The Thornthwaite Monthly Water Balance (TMWB) model $[24,25]$ was used to study the basin hydrology. The TMWB model is a robust non-data intensive model requiring only mean monthly temperature $(T)$, monthly total precipitation $(P)$ and latitude (in decimal degree) of the study area [24,25]. The model selection is based primarily on two factors. Most of the countries in emerging regions have very limited data. TMWB model is one of the non-data intensive models and it has proven its utility to analyze monthly hydrology in different parts of the world.The model is calibrated for 1990-1999 for which the in-situ data is available for temperature, precipitation and runoff. During calibration a one-year warming up period was used. The quantitative comparison between simulated and observed runoff was done using the percentage bias (Bias) and correlation coefficient (CC). First, reduction of bias is taken as the main objective in order to best match the total runoff volume generated by the model (simulated) to the observations, with the ideal case having a zero bias within the basin for the calibration period. For testing the goodness of fit of simulated runoff the CC was used. The calibrated model for $1990-1999$ shows a bias of $10.68 \%$, predicting higher runoff for the decade than actual observation. Although the model matches the runoff volume fairly well, it failed to match the peak over $100 \mathrm{~mm} / \mathrm{month}$ (Fig. 5a). The model captured the seasonality in general but the simulated runoff exceeded observed runoff during the wet seasons (Fig. $5 b)$.
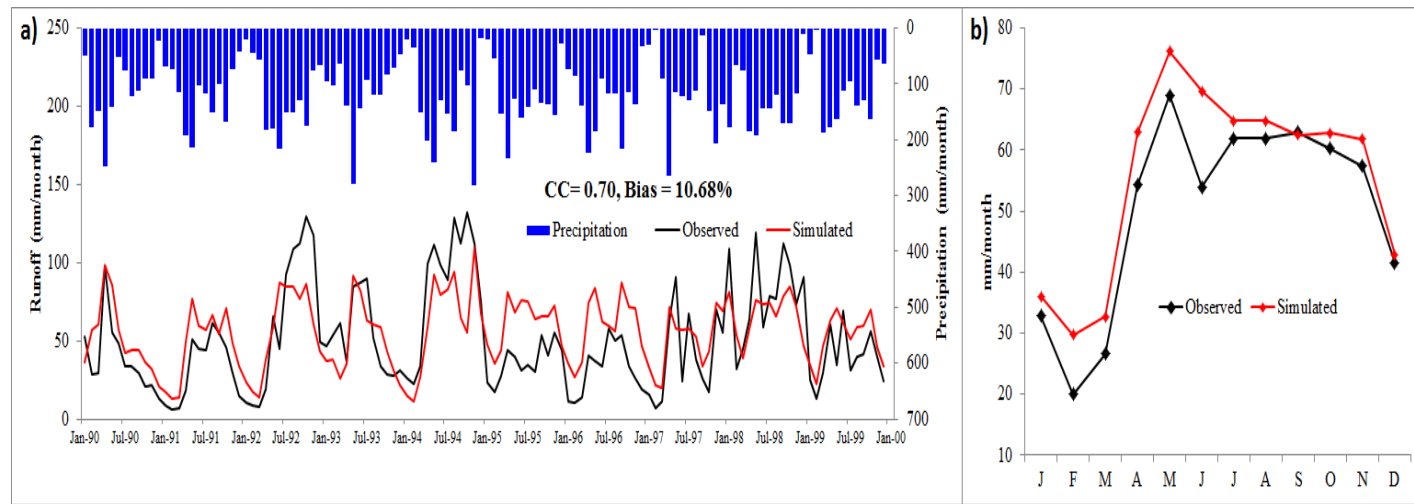

Fig. 5. Calibration TMWB model a) Calibration for the period 1990-1999, b) Seasonal runoff for the calibration period 
The calibrated model is used to benchmark precipitation $(\mathrm{P})$, potential and actual evapotranspiration (PET and AET) and runoffs (R) for the 1990-1999. The calibrated model and the bias corrected climatic data (Temperature and Precipitation) were then employed to project the states of the hydrological components for the coming decades: 2020-2029 (2020s), 2060-2069 (2060s) and 2090-2099 (2090s). Finally, the basin average decadal and seasonal analyses of the hydrological components ( $P, A E T$ and $R$ ) were conducted to determine the impact of climate change and water availability over the coming decades (2020s, 2060s and 2090s) compared to the 1990s.

\section{RESULTS AND DISCUSSION}

\subsection{Changes in Temperature}

The observed temperature shows an increasing trend since the 1990s. This increasing trend is expected to continue as shown by the climate projection data. All scenarios have almost the same rate of increase in mean annual temperature until 2030. Thereafter, for the B1 case, the rate of increase in temperature is less compared to the A2 and A1B scenarios (Fig. 6). At the end of the century, for the A2, A1B and B1 emissions scenarios, temperature is expected to increase in the basin by about $4.5,3.5$ and $2^{\circ} \mathrm{C}$, respectively.
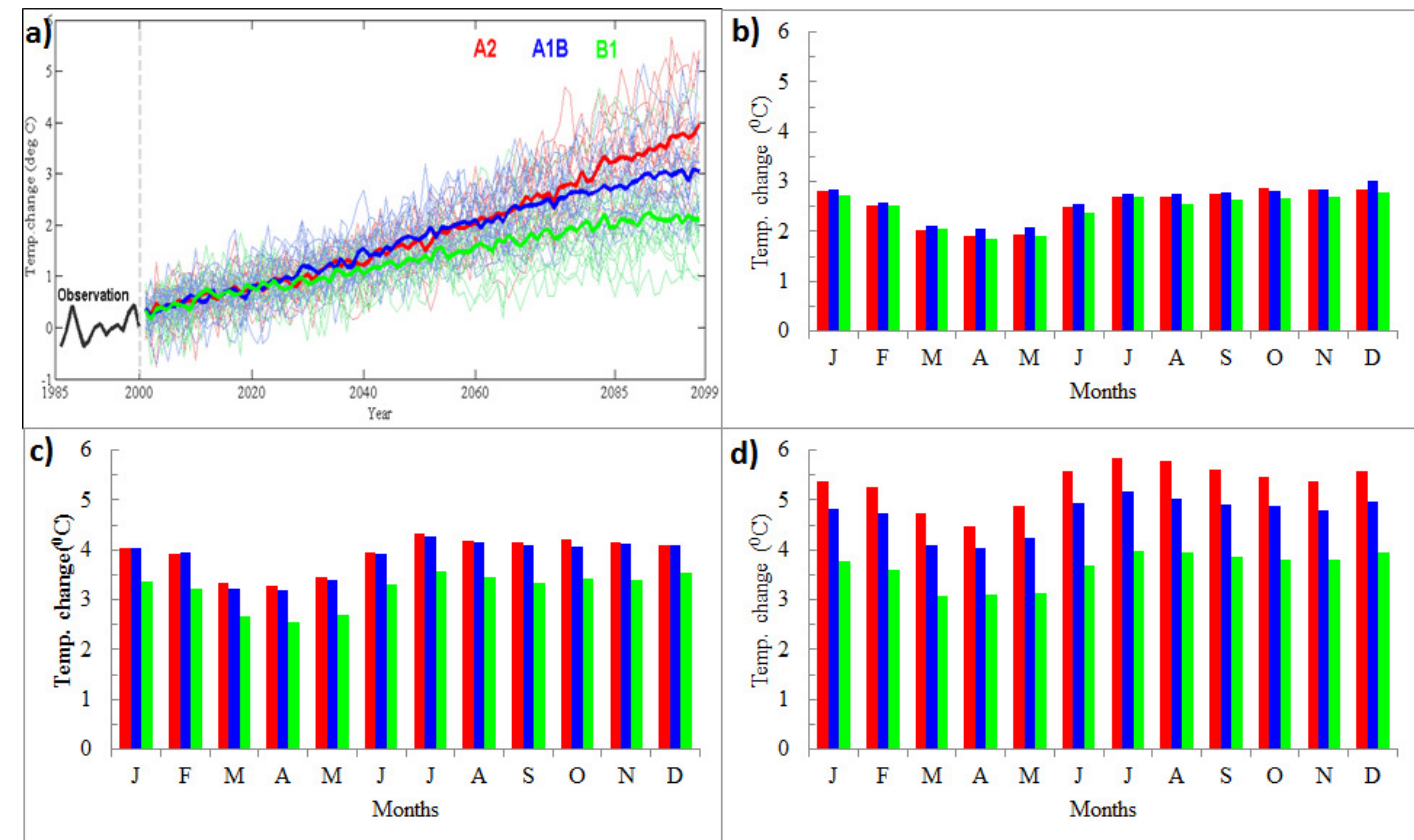

Fig. 6. a) Anomaly in temperature compared to the 1990-1999 for the A2, A1B and B1 scenarios, a) time series for 2000-2099 and seasonal anomalies for b) 2020-2029, c) 2060-2069 and d) 2090-2099

The seasonal temperature anomaly shows that the month of July and December is expected to witness a maximum change in temperatures in most of the scenarios and time periods. For the 2020s the maximum increment of 3 and $3.6^{\circ} \mathrm{C}$ is expected to occur in the month of December for medium to lower emission scenarios respectively. For 2060 s and 2090s 
though, July is projected to witness the highest changes in all emission scenarios often with more than $4^{\circ} \mathrm{C}$ (Fig. 6 ).

\subsection{Changes in Precipitation}

The Nzoia basin is expected to receive higher precipitation in the coming decades compared to 1990-1999 (Fig. 7). There is a marginal decrease in precipitation until the 2030s and almost no change until 2050. Still, the second half of the century is expected to be wetter. Changes in annual precipitation of almost 15,10 and $5 \%$ for the A2, A1B and B1 scenarios are projected by the end of the century.
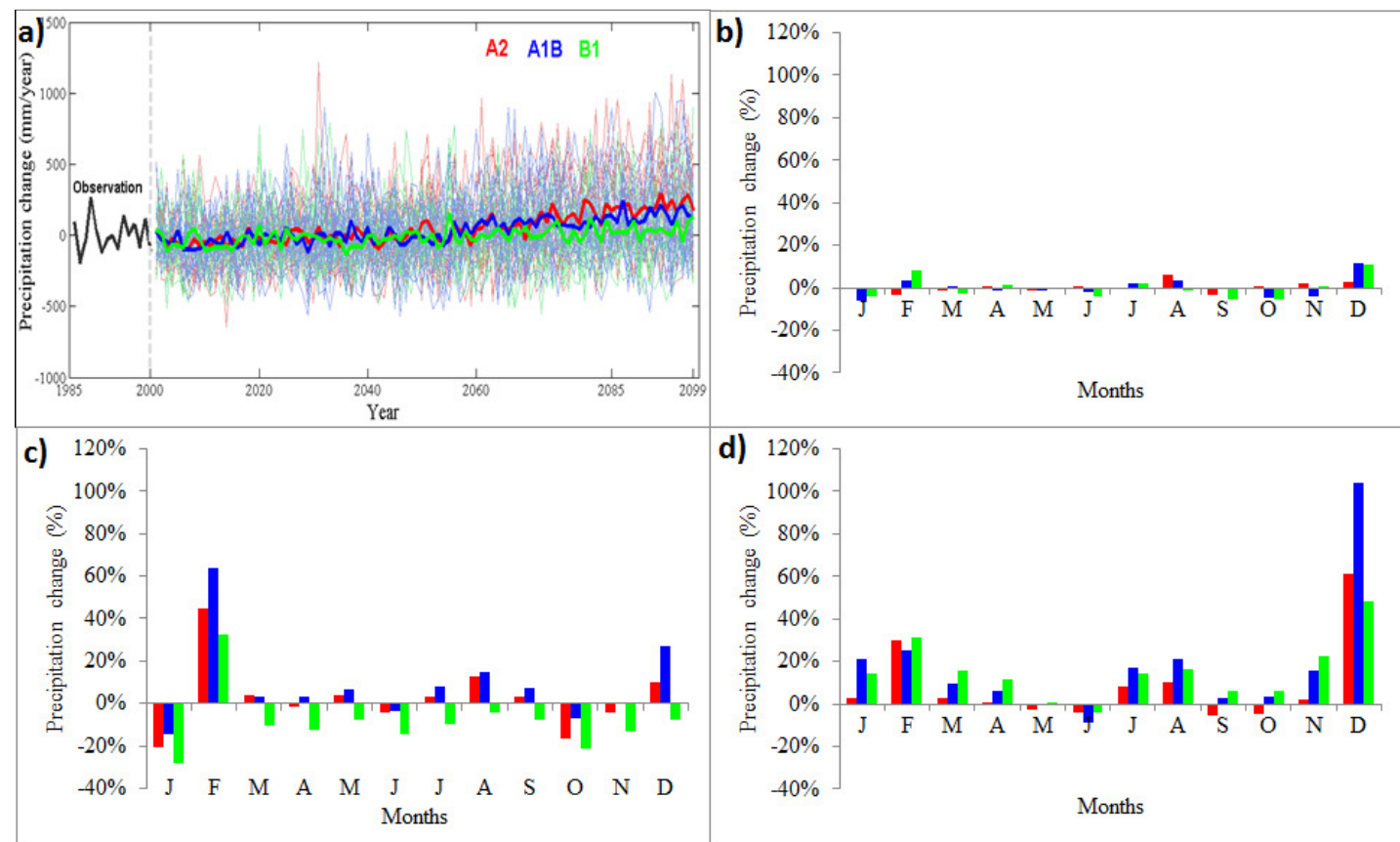

Fig. 7. a) Percentage anomaly in precipitation compared to the 1990-1999 for the A2, A1B and B1 scenarios, a) time series for 2000-2099 and seasonal anomalies for b) 2020-2029, c) 2060-2069 and d) 2090-2099

The seasonal precipitation values show that in the 2020s, most of the months are projected to receive less precipitation in all emission scenarios, except for December which is projected to be wetter by $2-12 \%$. In the 2060 s, most of the months are wetter in medium (A1B) and high emissions (A2) scenarios except for January and October, but February is projected to be wettest by almost $30 \%$ (B1) to 65\% (A1B) compared to the base period of the 1990s. In the 2090s, all months are expected to receive more rain, however, December is the wettest in all emissions scenarios, from 50\% (B1) to 125\% (A1B) (Figs. 7b,7c and 7d).

\subsection{Decadal Anomaly in Hydrology}

The calibrated model is then used to benchmark the hydrological components for the base period of 1990-1999 and to project their states in the future. The changes expected in short-, mid- and long-term are tabulated below (Table 3a, 3b and 3c). 
Table 3a. Decadal anomaly in hydrological components compared to the 1990s in scenario A2

\begin{tabular}{|c|c|c|c|c|}
\hline \multirow[t]{2}{*}{ Components } & \multirow[t]{2}{*}{ 1990-1999 } & \multicolumn{3}{|c|}{ A2: Changes over the base period } \\
\hline & & 2020-2029 & 2060-2069 & 2090-2099 \\
\hline Precipitation (mm/month) & 120.1 & $-0.9(-0.7 \%)$ & $6.4(5.4 \%)$ & $19.0(15.8 \%)$ \\
\hline PET (mm/month) & 70.5 & $3.8(5.3 \%)$ & $10.4(14.8 \%)$ & $17.7(25.1 \%)$ \\
\hline AET (mm/month) & 65.1 & $7.8(12.0 \%)$ & $14.4(22.2 \%)$ & $22.3(34.2 \%)$ \\
\hline Runoff (mm/month) & 55.1 & $-8.7(-15.8 \%)$ & $-8.0(-14.5 \%)$ & $-3.3(-6.0 \%)$ \\
\hline
\end{tabular}

Table 3b. Decadal anomaly in hydrological components compared to the 1990 s in scenario A1B

\begin{tabular}{|c|c|c|c|c|}
\hline \multirow[t]{2}{*}{ Components } & \multirow[t]{2}{*}{ 1990-1999 } & \multicolumn{3}{|c|}{ A1B: Changes over the base period } \\
\hline & & 2020-2029 & 2060-2069 & 2090-2099 \\
\hline 1 & & -0.7 & & $.4 \%)$ \\
\hline PE & 70.5 & 4.1 & $.3 \%)$ & $14.2(20.1 \%)$ \\
\hline (mm/month) & 65.1 & $8.1(12.5 \%)$ & $14.6(22.1 \%)$ & $19.4(29.2 \%)$ \\
\hline Runoff (mm/month) & 55.1 & $-8.7(-15.9 \%)$ & $-6.5(-11.8 \%)$ & $-5.8(-10.3 \%)$ \\
\hline
\end{tabular}

Table 3c. Decadal anomaly in hydrological components compared to the 1990 s in scenario B1

\begin{tabular}{lllll}
\hline Components & $\mathbf{1 9 9 0 - 1 9 9 9}$ & \multicolumn{3}{c}{ B1: Changes over the base period } \\
\cline { 2 - 5 } & & $\mathbf{2 0 2 0 - 2 0 2 9}$ & $\mathbf{2 0 6 0 - 2 0 6 9}$ & $\mathbf{2 0 9 0 - 2 0 9 9}$ \\
\hline Precipitation(mm/month) & 120.1 & $-0.1(-0.1 \%)$ & $2.1(1.7 \%)$ & $4.8(4.0 \%)$ \\
PET (mm/month) & 70.5 & $3.6(5.1 \%)$ & $7.4(10.5 \%)$ & $9.7(13.8 \%)$ \\
AET (mm/month) & 65.1 & $7.3(11.2 \%)$ & $10.9(16.7 \%)$ & $14.3(21.6 \%)$ \\
Runoff (mm/month) & 55.1 & $-7.3(-13.21 \%)$ & $-8.8(-15.9 \%)$ & $-9.5(-17.3 \%)$ \\
\hline
\end{tabular}

For both the $\mathrm{A} 2$ and $\mathrm{A} 1 \mathrm{~B}$ scenarios, the value of all major components of the hydrologic cycle, except the runoff, are expected to increase in coming decades over the base period of the 1990s. In the A2 scenario, runoff is projected to decrease by about $16 \%$ during the 2020 s and by about $6 \%$ in the 2090s. For the A1B scenario, the runoff is about $16 \%$ less in the 2020 s while it is about $10 \%$ less in the 2090 s compared to the 1990 s. The case in the B1 scenario differs slightly. Runoff is projected to be less by about $14 \%$ in the 2020 s and about $18 \%$ less for the 2090s. The situation in the later part of the century is the worst among three scenarios. The basin, as a result, will likely see a decrease in runoff in the coming decades.

\subsection{Seasonal Anomaly in Hydrology}

It is found that for the 1990s, the PET primarily followed the temperature and was lowest for the month of July (67 mm/month) while it was highest for March $(79 \mathrm{~mm} / \mathrm{month})$. Months from June to September were the coolest months in the Nzoia basin. From April to November, the AET is close to PET while for the rest of the months AET is much less than PET (Table 4).

The seasonal anomalies of the key hydrological components for the different scenarios are presented below (Figs. 8,9 and 10). 
Table 4. Seasonal P, T and estimated PET and AET over the basin

\begin{tabular}{|c|c|c|c|c|c|c|c|c|c|c|c|c|}
\hline & Jan & Feb & Mar & Apr & May & Jun & Jul & Aug & Sep & Oct & Nov & Dec \\
\hline $\mathrm{P}(\mathrm{mm})$ & 60.5 & 64.5 & 118.2 & 204.8 & 183.9 & 127.4 & 121.7 & 132.6 & 119.8 & 135.0 & 126.5 & 46.8 \\
\hline $\mathrm{T}\left({ }^{\circ} \mathrm{C}\right)$ & 19.7 & 20.3 & 21.0 & 20.5 & 19.9 & 19.0 & 18.3 & 18.5 & 19.0 & 19.3 & 19.2 & 19.1 \\
\hline PET (mm) & 72.3 & 68.0 & 78.7 & 74.3 & 74.3 & 67.9 & 67.1 & 67.7 & 67.2 & 70.9 & 67.5 & 69.5 \\
\hline AET (mm) & 47.7 & 47.0 & 75.6 & 74.3 & 74.3 & 67.9 & 67.1 & 67.7 & 63.8 & 70.9 & 67.5 & 57.0 \\
\hline
\end{tabular}


In the A2 scenario, precipitation is almost at the same level as that of the 1990s from January to July, except in the 2090s. During this timeframe, January-March was wetter than the 1990s. August and December are expected to receive higher precipitation than the 1990s for all decades. A continuous increment of AET over the baseline period of the 1990s is noted so as the increase in temperature and precipitation. In contrast, runoff is projected to reduce from the 1990s level. Runoff reduction is highest in the drier months (Fig. 8) indicating drier months getting even drier.

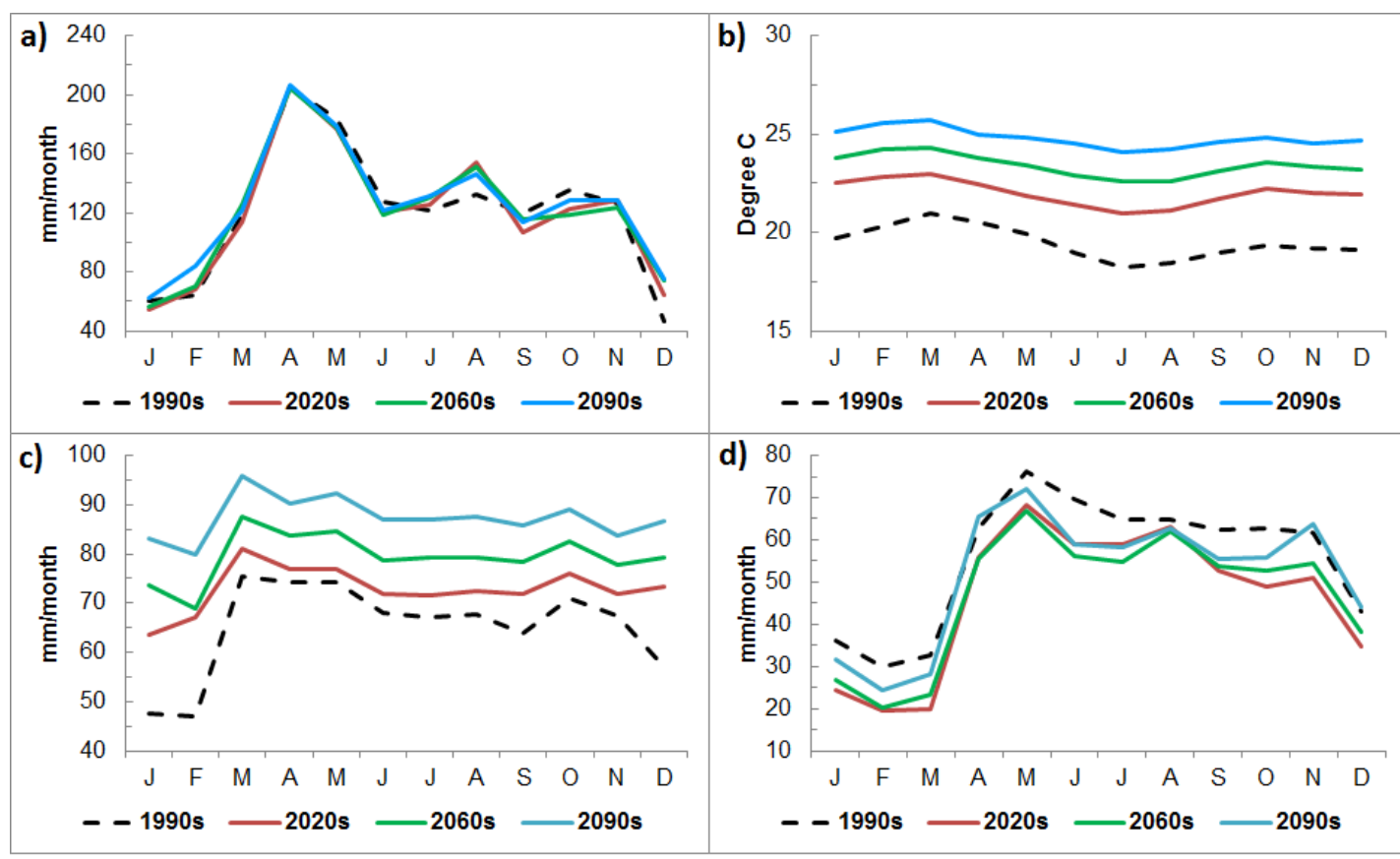

Fig. 8. Projected seasonal changes for the major hydrologic components a) Precipitation, b) Temperature, c) AET, and d) Runoff compared to the 1990-1999 for the A2 scenario

As in the A2 scenario, A1B also is expected to receive almost the same seasonal precipitation over the coming decades as that of the 1990s, except in the first half of the year. In the second half of the year though, it is expected to receive higher precipitation in all decades. In terms of AET, a continuous increment over the baseline period of the 1990s is expected as in the A2 scenario. Runoff is expected to decrease from the 1990 s level as in the A2 scenario. Runoff reduction is highest in the drier months as in A2 (Fig. 9).

In the case of the B1 scenario, the 2090s show increasingly wetter trends in precipitation, except during May-June, which is expected to see no change in precipitation through all three decades. No change in precipitation is projected for the 2060s, but the 2020s are projected to be drier in June, September and October. AET is expected to increase continuously over the baseline period of the 1990s as a result of a rise in temperature and availability of more precipitation as in the A2 and A1B scenarios. In contrast, runoff is projected to reduce from the 1990s level. Runoff reduction is highest in the drier months as in A2 (Fig. 10). 

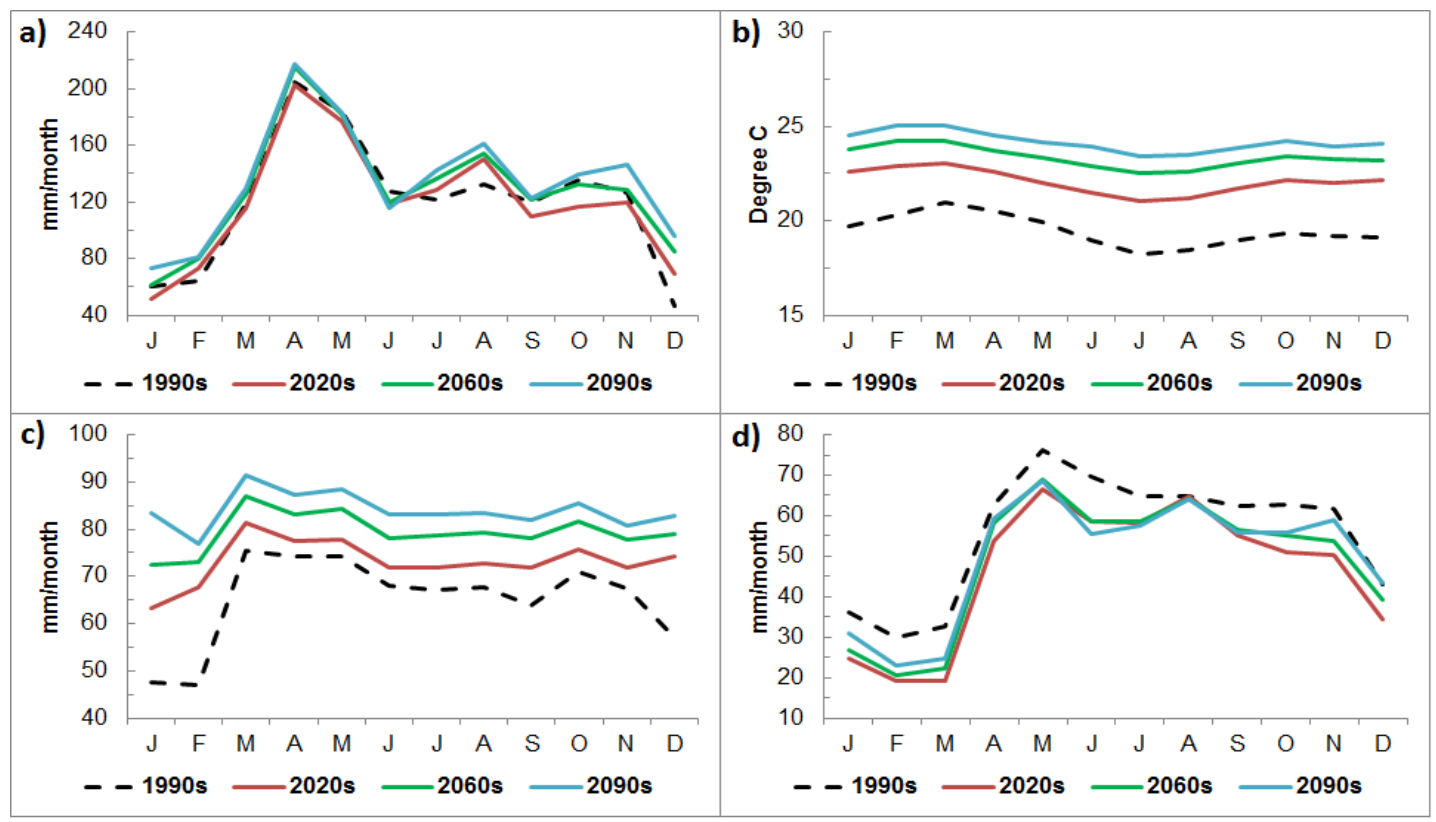

Fig. 9. Projected seasonal changes for the major hydrologic components a) Precipitation, b) Temperature, c) AET, and d) Runoff compared to the 1990-1999 for the A1B scenario
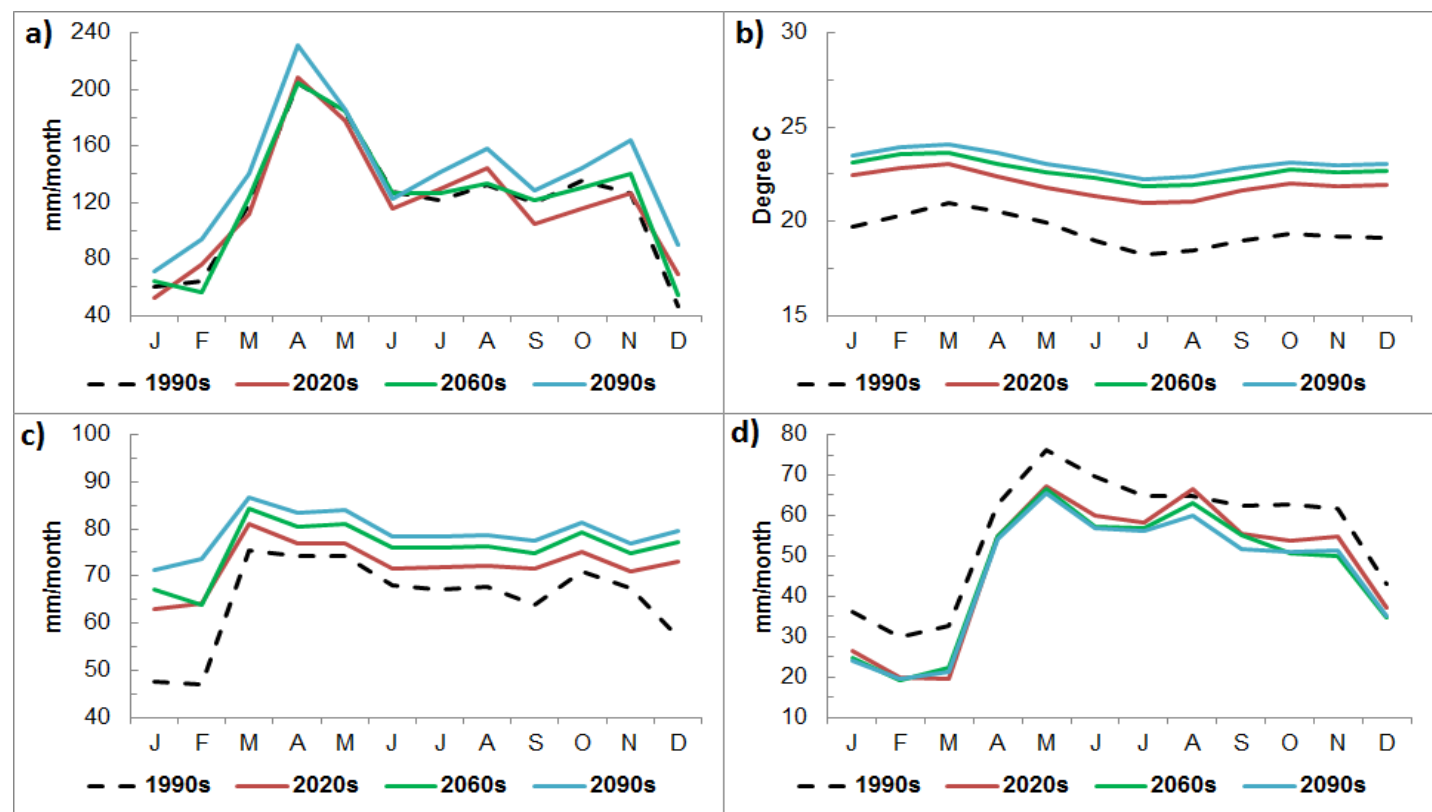

Fig. 10. Projected seasonal changes for the major hydrologic components a) Precipitation, b) Temperature, c) AET and d) Runoff compared to the 1990-1999 for the B1 scenario 
For Nzoia, in all emission scenarios, AET is projected to increase substantially in the drier season compared to the wetter season. The increase in the AET trend is driven mainly by higher temperature and precipitation. In general, an increase in seasonal precipitation is projected in all decades, but the runoff is expected to decrease. The decrement is very high in March and is less in August. In the A2 scenario for the 2090s, April, November and December are expected to receive much higher precipitation compared to the 1990s. Along with the increase in temperature, AET is also predicted to increase, subsequently reducing runoff and low water availability for consumption, which may potentially cause drought in the region.

\subsection{Seasonal Anomaly in Runoff}

To assess the surface water availability (i.e. runoff), from the above findings, seasonal streamflow plots were introduced for the short- and long-terms (2020s and 2090s, respectively) under the high $\mathrm{A} 2$ and low $\mathrm{B} 1$ emissions scenarios (Fig. 11).

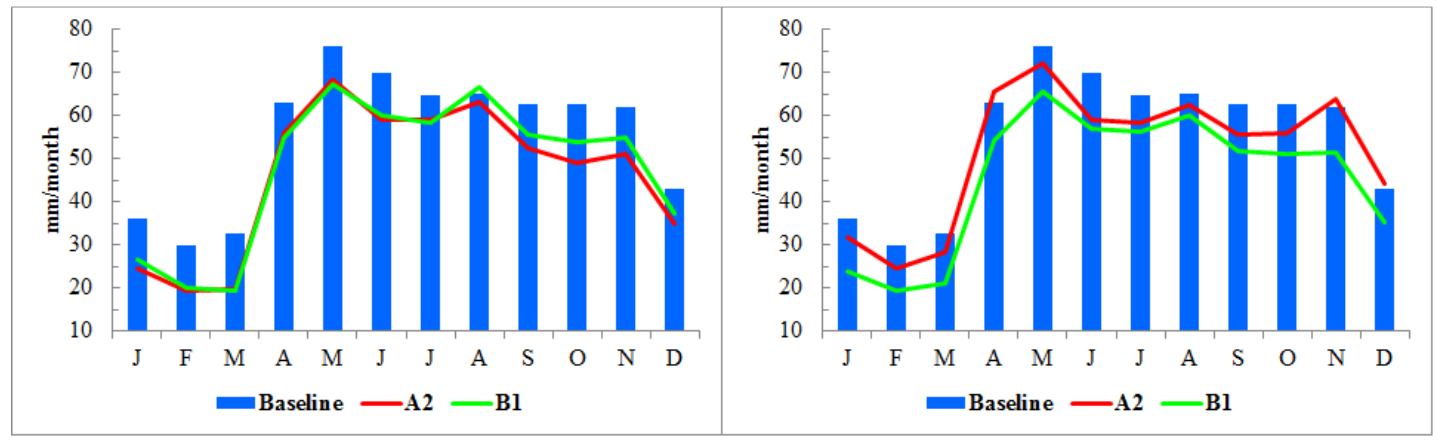

Fig. 11. Surface water anomaly (i.e., runoff) for the 2020s and 2090s in higher and lower emissions scenarios over the study basin

In general, a reduction in water availability is expected both in the short-term (2020s) and long-term (2090s) in all months irrespective to the emissions scenarios. In the short-term (2020s), the first half of the year expected to see higher reduction in runoff ranging from -14 to $-40 \%$ in both emissions scenarios, A2 and B1. With a slight increase in the precipitation projection for the long term (2090's) though, the B1 scenario remains high, with a range of $14 \%$ to $-35 \%$ over the year. In the A2 scenario however, the runoff differs from the baseline period, ranging from 4 to $-18 \%$, which is much different from the higher precipitation projection from B1.In both cases though, it shows that the reduction in the water availability is expected to occur during the long rainy seasons in Nzoia, which may hamper the irrigation and cropping practices in the region.

\subsection{Climate Elasticity of Runoff}

One way to evaluate the sensitivity of climate change impact on water availability is to understand the elasticity of runoff $(R)$ to changes in climate variables such as precipitation $(\mathrm{P})$ and temperature $(\mathrm{T})[26,27]$. 
The change in runoff is normalized by the change in precipitation (eq. 1) and temperature (eq. 2) respectively.

$$
\begin{gathered}
\varepsilon_{P}=\frac{R_{\text {new }}-R_{\text {base }}}{P_{\text {new }}-P_{\text {base }}}=\frac{\Delta R}{\Delta P} \\
\varepsilon_{T}=\frac{R_{\text {new }}-R_{\text {base }}}{T_{\text {new }}-T_{\text {base }}}=\frac{\Delta R}{\Delta T}
\end{gathered}
$$

Where,

$R_{\text {base }}, P_{\text {base }}, T_{\text {base }}$ are the average monthly runoff $(\mathrm{mm} / \mathrm{month})$, precipitation $(\mathrm{mm} / \mathrm{month})$, and temperature $\left({ }^{\circ} \mathrm{C}\right)$ respectively for the $1990 \mathrm{~s}$ based on observation data.

$R_{\text {new }}, P_{\text {new }}, T_{\text {new }}$ are the average monthly runoff $(\mathrm{mm} / \mathrm{month})$, precipitation $(\mathrm{mm} / \mathrm{month})$ and temperature $\left({ }^{\circ} \mathrm{C}\right)$ respectively. These are modeled results for the 2020s, 2060s and 2090s using GCM and Thornthwaite model projections as described in section 2.

Equations (1) and (2) are used to analyze the change in runoff with the unit change in $\mathrm{P}$ and $\mathrm{T}$. Table 5 shows that the change in runoff is more sensitive to a unit change in temperature than to a unit change of the precipitation in Nzoia, especially for the medium and long-term such as the 2060s and 2090s, which confirms the Nzoia as a temperature dominated basin and the increase in temperature will be the controlling factor for a future drier environment. Still, for the short-term 2020s, marginal reduction in precipitation has caused a high $\varepsilon_{P}$ compared to that of $\varepsilon_{T}$. The $\varepsilon_{P}$ value for the $\mathrm{B} 1$ scenario is exceptionally high compared to $A 2$ and $A 1 B$, which could be an outlier due to the very small change of $P$. In the 2060s and 2090s, $\varepsilon_{P}$ are found to be varying from -4.27 to -0.17 while $\varepsilon_{T}$ varies from -5.40 to -0.91 $\mathrm{mm} /{ }^{\circ} \mathrm{C}$, showing that the sensitivity of the runoff attributes more to the increased unit temperature than to the increased unit precipitation in the later part of the $21^{\text {st }}$ century. 
Table 5. Climate sensitivity of runoff (R) in Nzoia basin

\begin{tabular}{|c|c|c|c|c|c|c|c|c|c|c|c|c|}
\hline \multirow[t]{2}{*}{ Scenarios } & \multicolumn{4}{|c|}{ 2020-2029 (2020s) } & \multicolumn{4}{|c|}{ 2060-2069 (2060s) } & \multicolumn{4}{|c|}{$2090-2099$ (2090s) } \\
\hline & $\varepsilon_{p}$ & $\Delta \mathbf{P}$ & $\varepsilon_{\mathrm{t}}$ & $\Delta \mathrm{T}$ & $\varepsilon_{p}$ & $\Delta \mathbf{P}$ & $\varepsilon_{\mathrm{t}}$ & $\Delta \mathrm{T}$ & $\varepsilon_{p}$ & $\Delta P$ & $\varepsilon_{\mathrm{t}}$ & $\Delta \mathrm{T}$ \\
\hline $\mathrm{A} 2$ & 10.15 & -0.86 & -10.24 & 0.85 & -1.24 & 6.44 & -3.57 & 2.24 & -0.17 & 4.81 & -0.91 & 3.63 \\
\hline $\mathrm{A} 1 \mathrm{~B}$ & 12.82 & -0.68 & -9.51 & 0.92 & -0.80 & 8.68 & -2.99 & 2.17 & -0.38 & 13.71 & -1.77 & 2.97 \\
\hline B1 & 107.79 & -0.07 & -9.01 & 0.81 & -4.27 & 2.06 & -5.40 & 1.63 & -1.98 & 4.81 & -4.55 & 2.10 \\
\hline
\end{tabular}

Where, $\varepsilon_{P}, \varepsilon_{T}, \Delta P$ and $\Delta T$ with corresponding units of $\mathrm{mm} / \mathrm{mm}, \mathrm{mm} /{ }^{\circ} \mathrm{C}, \mathrm{mm}$ and ${ }^{\circ} \mathrm{C}$ respectively. 


\section{CONCLUSION}

The Nzoia River basin ecosystem supports not only western Kenya but also the broader Lake Victoria region. This study identified some of the possible impacts on water availability and hydrology of the basin. The Nzoia climate projection clearly shows an overall increase in temperature and precipitation in all scenarios by the end of this century. As expected, the highest emission scenario projects a percentage increase in precipitation of about $15 \%$ while it is about $5 \%$ for the lowest emission scenario. Still, the 2 to $5^{\circ} \mathrm{C}$ increase in temperature, depending on the emission scenarios, is going to create an overall drier climate with reduced runoffs in the basin. The first half of the current century is projected to be slightly drier than the 1990s. The later part of the century is expected to receive more precipitation than the 1990 s, but the much higher increase of temperature in the second half of the century is likely going to create a drier climate due to higher evapotranspiration.

Compared to the base period of the 1990s, the seasonal trend also shows that all major hydrological components, except the runoff, are expected to increase over the coming decades in all three emissions scenarios. Higher precipitation along with an increase in temperature is projected to intensify the actual evapotranspiration. The significant changes in actual evapotranspiration resulted in a lower runoff, even with the higher precipitation over the basin under the high emission scenario. For A2, the runoff is projected to decrease by about $17 \%$ during the 2020's while during the 2090's, marginal improvement will occur compared to the 2020s as runoff will be about $7 \%$ less. The case in the lower emission scenario is slightly different than the other two scenarios where runoff decreases continuously, from $14 \%$ less during the 2020 s to $18 \%$ less during the 2090 s. The climate elasticity of the runoff analysis also found that for the later part of the $21^{\text {st }}$ century, runoff tends to be more sensitive to the higher temperature than precipitation.

The projection for precipitation and temperature shows similar trends with other studies conducted in the Nzoia basin. However, it should be noted that those studies did not look into other components of the hydrologic cycles such as runoff and AET. This study projected an overall drier climate with less runoff in the future, compared to 1990 s levels, potentially impacting the domestic water supply, agriculture and overall environmental sustainability of the Nzoia basin. The main planting season in western Kenya is during the long-season rains between mid-February and mid-April. Any decrease in runoff or surface water availability, which is the very likely situation as a result of climate change, is expected to negatively impact the production of crops and potentially threaten the food security in the region.

\section{ACKNOWLEDGEMENTS}

This study is supported by NASA Applied Science Global Flood and Landslide Project, NASA SERVIR-Africa Project and School of Civil Engineering and Environmental Science at the University of Oklahoma. The authors would like to extend sincere thanks to the modeling groups, the Program for Climate Model Diagnosis and Intercomparison (PCMDI) and the WCRP's Working Group on Coupled Modeling (WGCM) for their roles in making available the WCRP CMIP3 multi-model dataset which is supported by the Office of Science, U.S. Department of Energy. Thanks also go to the Africa Regional Center for Mapping of Resources for Development (RCMRD) for making available the rainfall and discharge data at the study basin. We would also like to express our thanks to the three anonymous reviewers. A special thanks to Mr. Brian Squitieri, a meteorology senior at the University of Oklahoma for editing the manuscript. 


\section{COMPETING INTERESTS}

Authors have declared that no competing interests exist.

\section{REFERENCES}

1. Intergovernmental Panel on Climate Change (IPCC). Climate Change 2007: The Physical Science Basis. Contribution of Working Group I to the Fourth Assessment Report of the Intergovernmental Panel on Climate Change [Solomon, S., D. Qin, M. Manning, Z. Chen, M. Marquis, K.B. Averyt, M. Tignor and H.L. Miller (Eds.)], Cambridge University Press, Cambridge, United Kingdom and New York, USA; 2007.

2. Parry ML, CanzianiOF, Palutikof JP, van der Linden PJ, Hanson CE, editors. Contribution of Working Group II to the Fourth Assessment Report of the Intergovernmental Panel on Climate Change, Cambridge University Press; 2007.

3. Bates BC, Kundzewicz ZW, Wu S, Palutikof JP, editors. Climate change and water. Technical paper of the Intergovernmental Panel on Climate Change, IPCC Secretariat, Geneva; 2008.

4. Associated Program on Flood Management (APFM). Flood management in a changing climate: A tool for integrated flood management; 2009 [cited 2010 August 20]. Available from: www.apfm.info/pdf/ifm.../Tools FM in a changing climate.pdf.

5. Chahine MT. The hydrological cycle and its influence on climate. Nature. 1992;359:373-380.

6. Chipanshi AC, Chanda R, Totolo O. Vulnerability assessment of the maize and sorghum crops to climate change in Botswana. Clim Change. 2003;61:339-360.

7. FEWSNET. A Climate Trend Analysis of Kenya, USGS and USAID; 2010 [cited 2010 August 25]. Available from: http://www.fews.net/docs/Publications/FEWS\%20Kenya\%20Climate\%20Trend\%20An alysis.pdf.

8. Desanker PV, Magadza C. Africa. In: McCarthy JJ, Canziani OF, Leary NA, Doken DJ, White KS (Eds.). Climate Change 2001: Impacts, Adaptation and Vulnerability. IPCC Working Group II, Third Assessment Report, Cambridge University Press.

9. Brown C, Meeks R, Hunu K, Yu W. Hydroclimate risk to economic growth in subSaharan Africa. Clim Change. 2011;106:621-647.

10. Vicente-Serrano SM, Beguería S, Gimeno L, Eklundh L, Giuliani G, Weston D, KenawyAEI, López-Moreno JI, Nieto R, Ayenew T, Konte D, Ardö J, Pegram GGS (2012). Challenges for drought mitigation in Africa: The potential use of geospatial data and drought information systems. Appl Geogr, 2012;34(0):471-486.

11. Dai A. Drought under global warming: A review. Wiley Interdisciplinary Reviews: Clim Change. 2011;2:45-65.

12. Food and Agriculture Organization (FAO).Climate change, water and food security. FAO Water reports, \# 36; 2011.

13. Dulo, SO, Odira PMA, Nyadwa MO, Okelloh BN. Integrated flood and drought management for sustainable development in the Nzoia River Basin. Nile Basin Water Science \& Engineering Journal. 2010;3(2):39-51.

14. Simiyu GM, Adams DD, Esipila T. Integrated assessment of land use changes, organic carbon, greenhouse gases and spring water variability in the middle Nzoia River catchment, Kenya, Final Project Report; 2008.

15. Chambwera M, Stage J. Climate change adaptation in developing countries: issues and perspectives for economic analysis. International Institute for Environment and Development (IIED), UK; 2010. 
16. Watkiss P, Downing T, Dyszynski J. AdaptCost Project: Analysis of the economic costs of climate change adaptation in Africa. UNEP, Nairobi; 2010.

17. Intergovernmental Panel on Climate Change (IPCC). Emissions scenarios: summary for policymakers. A Special Report of IPCC Working Group III; 2000.

18. Nzoia River Basin Management (NRBMI). A public and private partnership between water resources management authority and civil society, learning institutions and communities. Water Resources Management Authority; 2006.

19. Maurer EP, Brekke L, Pruitt T, Duffy PB. Fine-resolution climate projections enhance regional climate change impact studies. Eos Trans. AGU. 2007;88(47):504.

20. Liu L, Hong Y, Hocker JE, Shafer MA, Carter LM, Gourley JJ, et al. Analyzing projected changes and trends of temperature and precipitation in the southern USA from 16 downscaled global climate models. Theor Appl Climatol. 2012;109:345-360.

21. Liu L, Hong Y, Bednarczyk CN, Yong B, Shafer MA, Riley R et al. Hydro-climatological drought analyses and projections using meteorological and hydrological drought indices: a case study in blue river Basin, Oklahoma. Water Resour Manage. 2012;26:2761-2779.

22. Maurer EP, Ada JC, Wood AW. Climate model based consensus on the hydrologic impacts of climate change to the Rio Lempa basin of Central America. Hydrol Earth Syst Sci. 2009;13(2):183-194.

23. Meehl GA, Covey C, Delworth T, Latif M, McAvaney B, Mitchell JF, et al. The WCRP CMIP3 multimodel dataset. Bull. Amer. Meteor. Soc. 2007;88:1383-1394.

24. ThornthwaiteCW. An approach toward a rational classification of climate. Geographical Review. 1948;38(1):55-94.

25. McCabe GJ, Markstrom SL. A monthly water-balance model driven by a graphical user interface. U.S. Geological Survey Open-File report. 2007;1088.

26. Fu G, Stephen PC, Chiew FHS. A two-parameter climate elasticity of stream flow index to assess climate change effects on annual stream flow. Water Resour Res, 2007;43:W11419.

27. Sankarasubramanian A, Vogel RM. Climate elasticity of stream flow in the United States. Water Resources Research. 2001;37(6):1771-1781.

(c) 2013 Adhikari and Hong; This is an Open Access article distributed under the terms of the Creative Commons Attribution License (http://creativecommons.org/licenses/by/3.0), which permits unrestricted use, distribution, and reproduction in any medium, provided the original work is properly cited.

Peer-review history:

The peer review history for this paper can be accessed here: http://www.sciencedomain.org/review-history.php?iid=218\&id=10\&aid=1220 